\title{
Study of Lead Level During Pregnancy by Application of Synchrotron Radiation Micro XRF
}

\author{
Yongpeng Tong • Huibin Sun • Qi Luo • Jinxing Feng • \\ Xiaohong Liu • Feng Liang • Fen Yan • Ke Yang • \\ Xiaohan Yu • Yulan Li • Jianmin Chen
}

Received: 17 June 2010 / Accepted: 5 August 2010 /

Published online: 17 August 2010

(C) The Author(s) 2010. This article is published with open access at Springerlink.com

\begin{abstract}
In order to study the daily $\mathrm{Pb}$ absorption in fetus and to monitor the main $\mathrm{Pb}$ sources in prenatal fetus, we have investigated several cases of $\mathrm{Pb}$ distribution along the longitudinal axis of fetal hair. The changes of $\mathrm{Pb}$ levels in the pregnancy period, even the daily changes of $\mathrm{Pb}$ levels can be detected in the hair. Therefore, by analyzing the $\mathrm{Pb}$ distribution curves in the fetal hair and the living habits of their mothers, the main sources of $\mathrm{Pb}$ in the prenatal fetus can be evaluated. In our study, the main sources of $\mathrm{Pb}$ in the two cases of prenatal fetus studied here should be from the polluted aquatics.
\end{abstract}

Keywords Synchrotron radiation micro XRF analysis · Fetal hair · Lead

\section{Introduction}

Although lead poisoning is one of the oldest known work and environmental hazards, the modern understanding of the small amount of lead necessary to cause harm did not come about until the latter half of the twentieth century. No safe threshold for lead exposure has been discovered - that is, there is no known amount of lead that is too small to cause the

Y. Tong $\cdot$ H. Sun $\cdot$ Q. Luo

College of Physical Science and Technology, Shenzhen University, Shenzhen City,

Guangdong Province 518060, China

J. Feng $\cdot$ X. Liu

Children's Hospital of Shenzhen, Shenzhen City, Guangdong Province 518026, China

F. Liang $\cdot$ F. Yan $\cdot$ K. Yang $\cdot$ X. Yu $\cdot$ Y. Li

Shanghai Institute of Applied Physics, Shanghai 201800, China

J. Chen

PerkinElmer Instruments (Shanghai) Co., Ltd., Shanghai 201203, China

Y. Tong $(\bowtie)$

Institute of Nuclear Techniques, Shenzhen University, Nanhai Ave 3688, Shenzhen 518060, China

e-mail: yongpengt@yahoo.com.cn 
body harm [1]. The brain is the organ most sensitive to lead exposure [2]; therefore, children are at greater risk of lead neurotoxicity than adults are [3]. Evidence suggests that most of lead's effects on a child's central nervous system are irreversible [4]. Children with lead poisoning may thus have adverse health, cognitive, and behavioral effects that follow them into adulthood [5]. In 1991, the US Centers for Disease Control and Prevention (CDC) determined that primary prevention activities in children should begin at blood lead levels (BLLs) $>10 \mu \mathrm{g} / \mathrm{dL}$ [6]. However, studies have repeatedly linked BLLs $<10 \mu \mathrm{g} / \mathrm{dL}$ in children 1-5 years of age with decreased intelligence quotient (IQ) and impaired cognition [7], and associations with attention and behavior problems are becoming increasingly evident as well [8]. Strong and long-lasting neurobehavioral effects occur with BLLs as low as $2 \mu \mathrm{g} / \mathrm{dL}$ [9]. A recent risk assessment by the California Environmental Protection Agency calculated that a $1-\mu \mathrm{g} / \mathrm{dL}$ change in BLLs in the range of $1-10 \mu \mathrm{g} / \mathrm{dL}$ results in a population-level decrement of one IQ point [10]. Also, some of the behavioral effects described in adolescents with early-life $\mathrm{Pb}^{2+}$ exposure are similar to those expressed in schizophrenia patients $[11,12]$ and the emerging evidence from both human studies and animal studies suggest that prenatal $\mathrm{Pb}^{2+}$ exposure may be a higher environmental risk factor for a fetal brain and nervous system. So how to evaluate daily $\mathrm{Pb}$ absorption in fetus is a problem which needs to be solved now.

As hair is a site of excretion of essential, nonessential, and potentially toxic elements, the use of hair as a biopsy material for drug abuse detection has grown in recent years. An element irreversibly incorporated into growing hair during the process of keratinization is often proportional to the level of the element in other body tissues. Thus, elemental analysis in hair has been used as a screening test for physiological excess, deficiency, or maldistribution [13]. Clinical research also indicates that hair levels of toxic elements such as arsenic, lead, mercury, cadmium, etc. are highly correlated with pathological disorders [14]. Especially, as shown in our previous report [15], the distribution of unnecessary element such as $\mathrm{Pb}$ can also be analyzed by synchrotron radiation Micro XRF along the longitudinal axis of a fetal hair. From the $\mathrm{Pb}$ distribution along the longitudinal axis of a fetal hair, the daily $\mathrm{Pb}$ absorption in fetal tissues 1-2 months before birth can be evaluated and monitored in. Therefore, by analyzing the $\mathrm{Pb}$ distribution curves in hair and $\mathrm{Pb}$ contents in several main environmental samples, a specific period of $\mathrm{Pb}$ environmental exposure history can be tracked and discussed. So hair $\mathrm{Pb}$ analysis by synchrotron radiation micro XRF can be used to reveal the main way of environmental $\mathrm{Pb}$ exposure at early stage.

\section{Material and Methods}

1. Subjects: The 10 uncontaminated fetal hair samples were collected from the back heads of those newborns (three girls, six boys) born between May and June of 2009 in Shenzhen Children's Hospital. Among those samples, two strands of hair were collected from one boy for $\mathrm{Pb}$ identical distribution analysis and one strand of hair was collected respectively from the other children.

2. Sample processing: The collected hair samples were never dyed or treated by chemical agents. Hair samples were washed three times with ethanol and wiped with nylon cloths then washed with pure water. After drying in air, the hair $1.5 \mathrm{~cm}$ in length was fastened by tape onto a sample holder.

3. XRF analysis: The micro XRF analysis was carried out in BL15U1 beam line of SSRF (Shanghai Synchrotron Radiation Facility). The hard X-ray energy and flux range $(6 \times$ $1,010 \mathrm{phs} / \mathrm{s}$ at $10 \mathrm{keV}, 200 \mathrm{~mA}$, and 16-18 keV) and the beam spot $(100 \times 300 \mu \mathrm{m})$ 


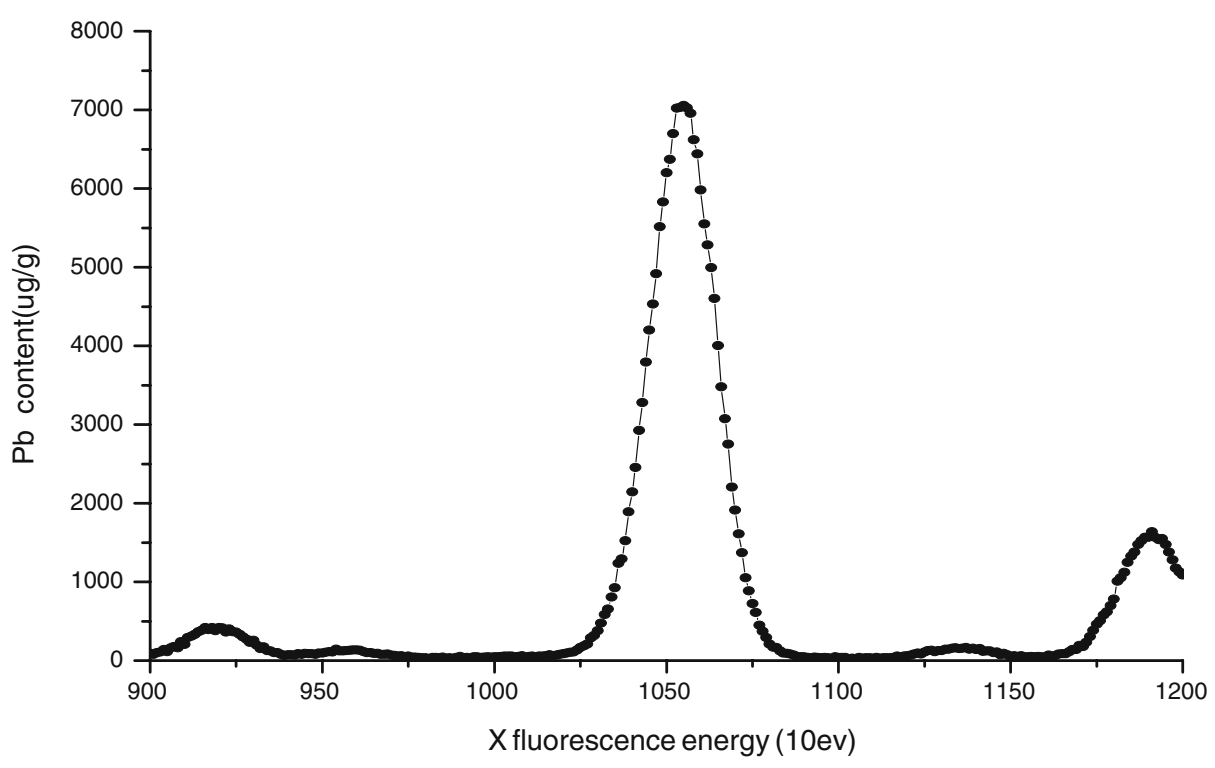

Fig. $1 \mathrm{~Pb}$ X-fluorescence spectrum of Cladophora in Synchrotron radiation XRF

were used for XRF analysis. Each hair has been scanned by XRF analysis. Experiments used the national standard hair samples of adult $(\mathrm{Pb} 3.83 \mathrm{mg} / \mathrm{kg}$; GBW09101) for calibration. After deduction of blank area and normalized by the Compton peak, the $\mathrm{Pb}$ peak area can be integrated. Then the content $\mathrm{Pb}$ can be calculated by comparing with the external standard (GBW09101, dry $3.83 \mathrm{mg} / \mathrm{kg}$ ).

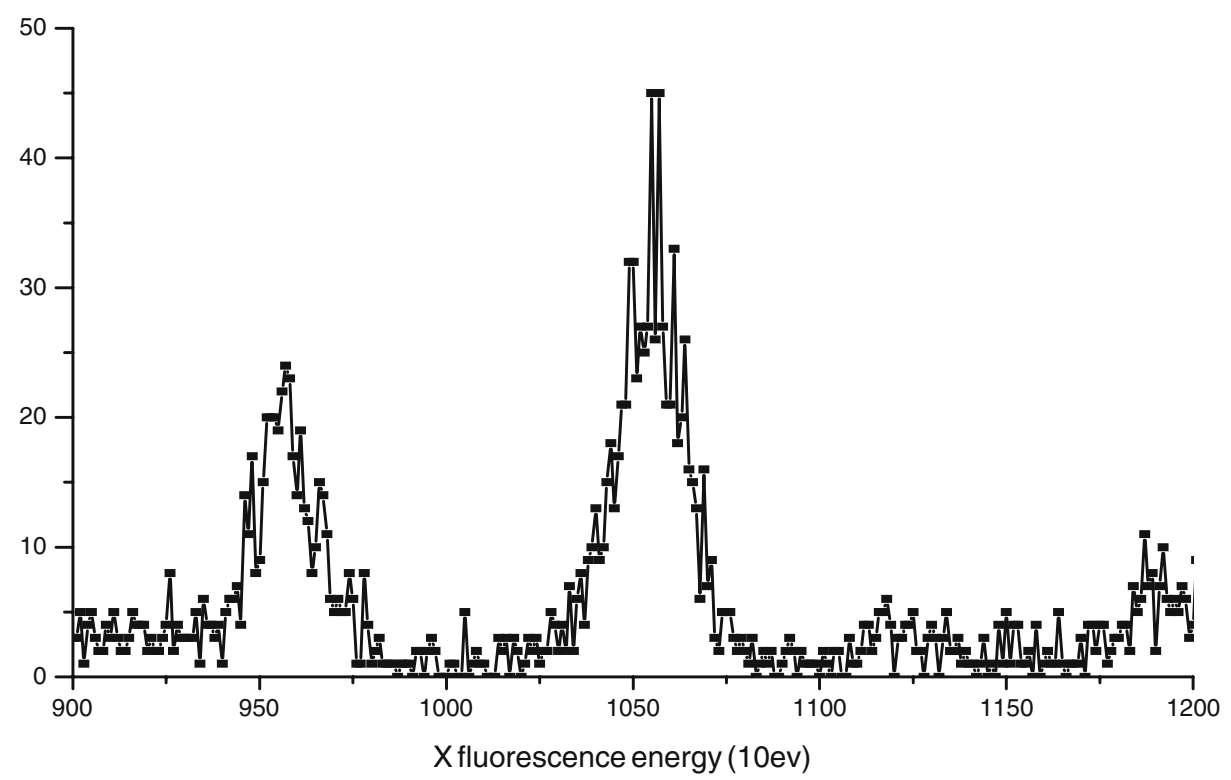

Fig. $2 \mathrm{~Pb} \mathrm{X}$-fluorescence spectrum of one hair in Synchrotron radiation XRF 
Table 1 Comparison of $\mathrm{Pb}$ content got from Synchrotron radiation XRF analysis and from ICP analysis

\begin{tabular}{lll}
\hline & Soil of Shenzhen University(5) & Pb-rich Cladophora (5) \\
\hline Micro-XRF analysis & $24 \pm 2 \mathrm{mg} / \mathrm{kg}$ & $3,308 \pm 280 \mathrm{mg} / \mathrm{kg}$ \\
(ICP analysis) & $25 \pm 1 \mathrm{mg} / \mathrm{kg}$ & $3,569 \pm 80 \mathrm{mg} / \mathrm{kg}$ \\
\hline
\end{tabular}

4. ICP analysis method: In order to study the relationship between $\mathrm{Pb}$ content in fetal hair and environmental $\mathrm{Pb}$ exposure, several kinds of environmental samples have been analyzed by ICP. Blood specimens and all environmental samples were analyzed by ICP-MS using standard mode without DRC gas (ELAN DRC II; PerkinElmer, USA). Standard addition calibration provided by the ELAN software was used for calibration. The field reagent blanks normally showed less than $0.5 \mu \mathrm{g} / \mathrm{L}$ lead in the final solution, which assured negligible contamination problems. The process can be referred in our previous report [16].

5. Statistical analysis: The student's $t$ test has been used for the statistical analysis here. All statistical test results were evaluated by using an overall significance level of $P<0.05$.

\section{Result and Discussion}

Determination of Pb Peak Position in XRF Fetal Hair Analysis In order to find the interference-free $\mathrm{Pb} \mathrm{X}$ emission fluorescence peak in the present experimental condition, the XRF spectrum of lead-rich Cladophora and the spectrum of one spot of no. 2 hair is shown in Figs. 1 and 2, respectively. By comparing Fig. 1 with Fig. 2, the $L_{\mathrm{Pb}}(10.25-$ $10.75 \mathrm{Kev}$ ) peak can be used for the determination of $\mathrm{Pb}$ level in our experiment. Therefore, several samples measured by XRF using this peak analysis and measured by ICP method have been compared in Table 1.

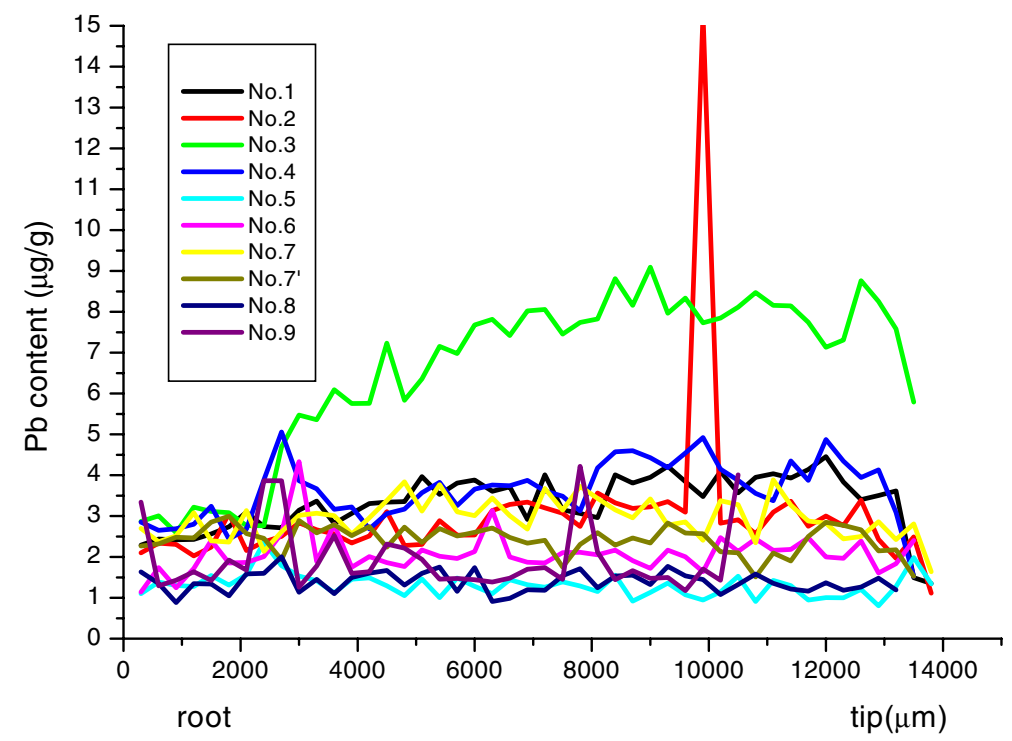

Fig. $3 \mathrm{~Pb}$ distribution along the longitudinal axis of those fetal hair got from synchrotron radiation XRF analysis 
Table $2 \mathrm{~Pb}$ contents of the urban environment

Sample $\mathrm{Pb}$ content $(\mathrm{mg} / \mathrm{kg}$ ) Fuyong town (no. of samples) Other districts of Shenzhen (no. of samples)

\begin{tabular}{lcc}
\hline Indoor residential dust & $194 \pm 45(5)$ & $181 \pm 117(5)$ \\
Water(pond and river) & $0.008 \pm 0.002(5)$ & $0.006 \pm 0.003(5)$ \\
${ }^{\mathrm{a}}$ Fish meat & $9.0 \pm 0.5(8)$ & $0.56 \pm 0.30(8)$ \\
\hline
\end{tabular}

${ }^{a}$ Significant difference of two columns

In Table 1, the difference between Pb level got from XRF and ICP is less than $8 \%$.

So it is credible to use synchrotron radiation XRF to determine $\mathrm{Pb}$ content in hair.

The Distribution of $\mathrm{Pb}$ in Fetal Hair Ten strands of fetal hair samples were analyzed by synchrotron radiation micro XRF analysis. The result was shown in Fig. 4. In Fig. 4, the Pb distribution along the strand of the hair can be revealed. As the hair grows every day, the $\mathrm{Pb}$ intake at different period can be evaluated through the $\mathrm{Pb}$ distribution curve. So a certain period of $\mathrm{Pb}$ exposure history can be tracked.

In Fig. 3, the $\mathrm{Pb}$ content of no. 3 (boy) hair was shown significantly higher than the others between 3,000 and 14,000 $\mu \mathrm{m}$ area from the root of the hair in which was grown during the period of 1 month before birth. The average $\mathrm{Pb}$ content there is about $6.6 \mathrm{mg} / \mathrm{kg}$ which is even higher than that of adult dry hair (3.83 mg/kg GBW09101), and is almost five times than the normal reported fetal hair result(boys hair $\mathrm{Pb}=1.15 \pm 0.93 \mathrm{mg} / \mathrm{kg}$, girls hair $\mathrm{Pb}=1.03 \pm 0.85 \mathrm{mg} / \mathrm{kg}$ ) [17]. From the result of environmental investigation and living habit investigation, it is known that the mother of no. 3 (boy) is living at Fuyong Town of Shenzhen, the other eight mothers are living in other Districts of Shenzhen. The Pb contents of environmental samples (indoor residential dust, water from pond and river and fish meat) at the two parts (Fuyong Town and other Districts of Shenzhen) have been compared in Table 2.

From the comparison in Table 2, we find that the $\mathrm{Pb}$ content in fish meat of Fuyong Town is significant higher than that of others. Furthermore, the mother living in Fuyong likes to eat fish in that period of 1-2 months before baby-birth. So the $\mathrm{Pb}$ intake may be from those eaten aquatics (fish etc.). As the mega city Shenzhen, located at The Pearl River Delta region in Guangdong Province is one of the most economically developed cities in South China, the industrial pollution is also relative higher than those other smaller cities. Furthermore, Fuyong town is near the Shenzhen Airport which is located in Baoan District of Shenzhen. There are lots of small factories concentrated in this town. From the environmental report 2007 of Bao'an District of Shenzhen [17], several rivers (Fuyong River, Sand Fu River etc.) are polluted and the water quality categories are V class. The aquatics (fish etc.) with higher $\mathrm{Pb}$ content can be found in supermarket. The lead enrichment by those aquatics may be a way of $\mathrm{Pb}$ intake for fetus in the pregnancy progress.

After 8 months of birth, the stature of no. 3 infant is grown from $51 \mathrm{~cm}$ to $65 \mathrm{~cm}$, the growth was less by $5 \mathrm{~cm}$ in height compared to the average height of other infants. Several

Fig. 4 The $\mathrm{Pb}$ scanning map $(6,000 \times 100 \mu \mathrm{m})$ of another hair of no. 2

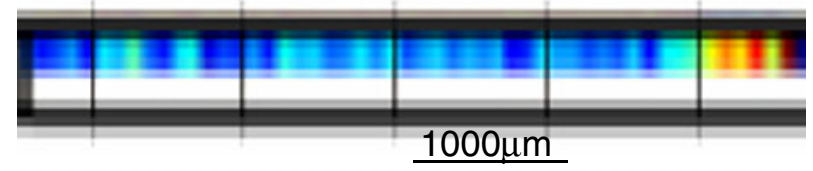


Table $3 \mathrm{~Pb}$ contents in sea foods of the restaurant

\begin{tabular}{lc}
\hline Sample (dry) & Pb content (mg/kg) (no. of samples) \\
\hline Abalonel meat & $5.9 \pm 3.0(5)$ \\
Crab meat & $25 \pm 10(5)$ \\
Crab paste & $20 \pm 5(5)$ \\
Octopus meat & $15 \pm 6(8)$ \\
Penaeus meat & $3.1 \pm 0.1(5)$ \\
Pakistan non-clam & $16 \pm 1(4)$ \\
Scallop meat & $5.6 \pm 0.5(5)$ \\
Squid meat & $13 \pm 3(5)$ \\
Baby lonia areolate & $42 \pm 4(5)$
\end{tabular}

similar studies have also shown that elevated blood lead $(\mathrm{Pb})$ levels in children are associated with decreased growth [18]. So it is a serious problem if there is higher $\mathrm{Pb}$ intake in prenatal fetus in the pregnancy progress.

In Fig. 3, a sharp peak in the hair Pb distribution curve of no. 2 infant (boy) in a certain period (from about 20 days before birth) is shown. The peak value is about $15.2 \mathrm{mg} / \mathrm{kg}$, which is much higher than that of Chinese state standard reference of adult hair (GBW09101, dry $3.83 \mathrm{mg} / \mathrm{kg}$ ), and the reported average hair result of normal fetus [19]. The Pb scanning map $(6,000 \times 100 \mu \mathrm{m})$ of another hair of no. 2 was shown in Fig. 4. In it, a $\mathrm{Pb}$ peak can also be found (red color) in the same period. The similar $\mathrm{Pb}$ peaks in the two strands of the boy's hair are reflecting his mother may have the possibility of acute $\mathrm{Pb}$ exposure during the period. After investigation, we learned that in that period of pregnancy, the pregnant women had gone to a sea food restaurant twice. Several kinds of sea foods she eaten in that restaurant were analyzed and the $\mathrm{Pb}$ content was listed in Table 3.

In Table 3, most $\mathrm{Pb}$ contents in those sea foods of the restaurant are beyond the value of Chinese Food Safety Standards (GB 14935-94, GB/T 5009.12). The sea foods with high Pb content eaten by the mother of no. 2 infant makes the high $\mathrm{Pb}$ level in the hair grown in that period. So the $\mathrm{Pb}$ intake can be monitored in the pregnancy progress by analyzing the $\mathrm{Pb}$ distribution along the longitudinal axis, thus, the way of $\mathrm{Pb}$ exposure may be tracked.

Usually, the serious pollution of $\mathrm{Pb}$ can be evaluated by the blood lead levels of local children. For comparison, the average children blood lead levels of Shenzhen and another Guangdong big city - Guangzhou was obtained by ICP measurement. The result was listed in Table 4. In Table 4, the average children blood lead levels of two cities were shown no significant different. The arithmetic average of blood lead level was $62 \pm 24 \mu \mathrm{g} / \mathrm{L}$ in Guangzhou and $61 \pm 31 \mu \mathrm{g} / \mathrm{L}$ in Shenzhen. The average blood lead level was in the acceptable range $(<100 \mu \mathrm{g} / \mathrm{L})$ suggested by American CDC in 1991 [6]. Obviously, it is difficult to monitor the way of $\mathrm{Pb}$ exposure by the one time-detection of children blood lead levels; however, the $\mathrm{Pb}$ distribution analysis in infant hair may do it.

Table 4 The BLLs and the prevalence of lead poisoning for children at the age of 2-12 years old collected in Guangzhou and Shenzhen

\begin{tabular}{lllc}
\hline Age & No. & BLLs (average) & Percentage BLLs $\geq 100 \mu \mathrm{g} / \mathrm{L}$ \\
\hline Guangzhou & 368 & $62 \pm 24$ & 10.3 \\
Shenzhen & 393 & $61 \pm 31$ & 8.9 \\
\hline
\end{tabular}




\section{Conclusion}

By synchrotron radiation micro-beam XRF analysis of multiple samples of fetal hairs, the $\mathrm{Pb}$ distribution along the longitudinal axis can be analyzed. Therefore, by analyzing the $\mathrm{Pb}$ distribution curves of hair, a certain period of $\mathrm{Pb}$ exposure history can be tracked. The main $\mathrm{Pb}$ sources of prenatal fetus should be from those polluted aquatics.

Acknowledgments This work was supported by National Science Foundation of China (10675159), supported by Shenzhen public scientific and technological project (SY200806270164A) and supported by the project (08sr0107) of BL15U1 of SSRF (Shanghai Synchrotron Radiation Facility). The authors declare that they have no competing financial interests.

Open Access This article is distributed under the terms of the Creative Commons Attribution Noncommercial License which permits any noncommercial use, distribution, and reproduction in any medium, provided the original author(s) and source are credited.

\section{References}

1. Barbosa F, Tanus-Santos JE, Gerlach RF, Parsons PJ (2005) A critical review of biomarkers used for monitoring human exposure to lead: advantages, limitations, and future needs. Environ Health Perspect 113(12):1669-1674

2. Cecil M, Brubaker J, Adler M, Dietrich N, Altaye M, Egelhoff C, Wessel S, Elangovan I et al (2008) Decreased brain volume in adults with childhood lead exposure. PLoS Med 5(5):e112

3. Sanders T, Liu Y, Buchner V, Tchounwou PB (2009) Neurotoxic effects and biomarkers of lead exposure: a review. Rev Environ Health 24(1):15-45

4. Bellinger DC (2004) Lead. Pediatrics 113(4 Suppl):1016-1022

5. Woolf A, Goldman R, Bellinger D (2007) Update on the clinical management of childhood lead poisoning. Pediatr Clin North Am 54(2):271-294

6. Atlanta GA, CDC (1991) Preventing Lead Poisoning in Young Children. Centers for Disease Control and Prevention

7. Bellinger DC, Needleman HL (2003) Intellectual impairment and blood lead levels. N Engl J Med 349:500-502

8. Braun JM, Kahn RS, Froehlich T, Auinger P, Lanphear BP (2006) Exposures to environmental toxicants and attention deficit hyperactivity disorder in U.S. children. Environ Health Perspect 114:1904-1909

9. Jusko TA, Henderson CR, Lanphear BP, Cory-Slechta DA, Parsons PJ, Canfield RL (2008) Blood lead concentrations $<10 \mu \mathrm{g} / \mathrm{dL}$ and child intelligence at 6 years of age. Environ Health Perspect 116:243-248

10. California Environmental Protection Agency (2009) Proposition 65 safe harbor levels: no significant risk levels for carcinogens and maximum allowable dose levels for chemicals causing reproductive toxicity. California Environmental Protection Agency, Office of Environmental Health Hazard Assessment, Sacramento

11. Opler MGA, Buka SL, Groeger J, McKeague I, Wei C, Factor-Litvak P et al (2008) Prenatal exposure to lead, $\delta$-aminolevulinic acid, and schizophrenia: further evidence. Environ Health Perspect 116:15861590

12. Guilarte TR (2009) Prenatal lead exposure and schizophrenia: further evidence and more neurobiological connections. Environ Health Perspect 117:A190-A191

13. Lin X, Alber D, Henkelmann R (2004) Elemental contents in Napoleon's hair cut before and after his death: did Napoleon die of arsenic poisoning. Anal Bioanal Chem 379(2):218-220

14. Legrand M, Lam R, Jensen-Fontaine $M$ et al (2004) Direct detection of mercury in single human hair by Coupled Plasma Mass Spectrometry (LA-ICP-MS). J Anal At Spectrom 19(10):1287-1288

15. Tong YP, Li CM, Luong JHT (2007) Probing calcium and sulfur distribution and pattern in hairs using micro-proton induced X-ray emission (MPIXE). Chinese Science Bulletin 52(21):2909-2912 
16. Chen J, Tan M, Li Y, Zhang Y, Lu W, Tong Y et al (2005) A lead isotope record of Shanghai atmospheric lead emissions in total suspended particles during the period of phasing out of leaded gasoline. Atmos Environ 39:1245-1253

17. Zhang B, Meng Z (2001) The study on zinc and lead levels in human hair. Urban Enviroment Urban Ecol 14(4):8-10

18. Baoan Environmental Protection Bureau, Shenzhen, Newsletter (2007) Issue 3 (Total 6) (Chinese unpublished internal net data http://www.szbaepb.gov.cn/govopen/detail.asp?class id=197\&id=826)

19. Little BB, Snell LM, Johnston WL, Knoll KA, Buschang PH (2005) Blood lead levels and growth status of children. Am J Hum Biol 2(3):265-269 